\title{
FAMÍLIA, EDUCAÇÃO E SOCIEDADE CONTEMPORÂNEA - A EDUCAÇÃO FAMILIAR COMO PROPOSTA À CONVERGÊNCIA DE UM PLANETA SUSTENTÁVEL
}

\section{FAMILY, EDUCATION AND CONTEMPORARY SOCIETY - FAMILY EDUCATION AS A PROPOSAL FOR THE CONVERGENCE OF A SUSTAINABLE PLANET}

\author{
Júlio César Bernardes ${ }^{1}$
}

Resumo: O presente artigo tem por objetivo discorrer sobre a educação familiar como processo de aprendizado primário do ser humano, justificando sua importância para o desenvolvimento da personalidade e crescimento cognitivo da criança e do adolescente, em especial, como instrumento de educação para a sustentabilidade. A educação familiar é recurso viável para a disseminação da educação para a sustentabilidade entre crianças e adolescentes. A implantação da cultura de sustentabilidade global e preservação do meio ambiente requer a aplicação de políticas públicas, projetos e ações por parte do Estado e da sociedade, voltados ao aprendizado desses temas no ambiente familiar. Para produção do texto utilizou-se, na fase de investigação e no relatório da pesquisa, o método indutivo.

Palavras chave: Educação Familiar. Sustentabilidade. Família.

Abstract: This article aims to discuss family education as a process of primary learning of the human being, justifying its importance for the development of personality and cognitive growth of children and adolescents, especially as an instrument for education for sustainability. Family education is a viable resource for the dissemination of education for sustainability among chil-

1 Juiz de Direito em Braço do Norte/SC, doutorando do Curso de Doutorado em Ciência Jurídica pela Universidade do Vale do Itajaí - UNIVALI, em regime de dupla titulação com a Universidade de Alicante - UA/Espanha, mestre em Ciência Jurídica pela UNIVAL, mestre em direito ambiental e sustentabilidade pela Universidade de Alicante - UA/Espanha, especialista em direito e gestão judiciária pela Academia Judicial do Tribunal de Justiça de Santa Catarina, graduado em direito pela Universidade do Extremo Sul Catarinense - UNESC. CV: http://lattes.cnpq.br/3990333915200360. Email: jcb22164@tjsc.jus.br. 
dren and adolescents. The implementation of the global sustainability culture and preservation of the environment requires the application of public policies, projects and actions by the State and society, aimed at learning these themes in the family environment. For the production of the text, the inductive method was used in the research phase and in the research report.

Keywords: Family Education. Sustainability. Family.

\section{INTRODUÇÃ̃O}

Este artigo científico tem por objetivo discorrer sobre a educação familiar como processo de aprendizado primário do ser humano, justificando sua importância para o desenvolvimento da personalidade e crescimento cognitivo da criança e do adolescente, em especial, como instrumento de educação para a sustentabilidade.

Assim, a importância do tema está em apontar a educação familiar como instrumento de concretização da educação para a sustentabilidade, destacando seu fundamental papel nesse processo para a renovação cultural dos habitantes do planeta em benefício das gerações presente e futuras.

Além disso, o suporte teórico a ser apresentado, ao final, fornecerá elementos ao Estado e à sociedade civil para compreender que a educação familiar deve ser por eles protegida e incentivada: por meio de políticas públicas, ações e medidas voltadas ao fortalecimento da Família ${ }^{2}$, para implementação de instrumentos que facilitem essa tarefa educativa no ambiente familiar.

Os resultados da pesquisa estão expostos no presente trabalho, de forma sintetizada, como segue.

Para alcançar o objetivo elencado acima, discorreremos inicialmente sobre a educação familiar, abordando a Família como primeiro agente de socialização da criança e o processo

2 No presente trabalho, a categoria Família é empregada com a inicial maiúscula, por ser a categoria objeto principal de estudo desta investigação e por entendermos que a ela foi designada uma função social imprescindível para a sustentabilidade do planeta, em razão de ser o núcleo base da Sociedade civil. 
sociocultural exercido no ambiente familiar.

No segundo tópico, explanaremos sobre a educação familiar como processo cognitivo cultural e biológico de processamento de informações pelo ser humano. Neste momento do trabalho demonstraremos a influencia dos aspectos socioculturais como modeladores do sujeito, a partir de um sistema de transmissãoaquisição que se inicia no momento do nascimento da criança.

No terceiro e último tópico, desenvolveremos a temática da educação para a sustentabilidade como escopo da função social da Família, evidenciando o importante papel da Família no processo de aprendizado e transmissão de conhecimentos às crianças e adolescentes.

Quanto à metodologia, na ase de investigação e no relatório da pesquisa, utilizou-se o método indutivo. Foram acionadas as técnicas do referente, da categoria, dos conceitos operacionais e da pesquisa bibliográfica.

\section{A EDUCAÇÃO FAMILIAR - A FAMÍLIA COMO PRIMEIRO AGENTE DE SOCIALIZAÇÃO DA CRIANÇA}

Na história da humanidade a Família sempre foi reconhecida como uma das instituições mais influentes e poderosas das sociedades humanas. Como destaca Cacharrón (1988, p. 184), já em Cícero a Família era compreendida como célula básica da sociedade, não apenas no aspecto biológico, mas também no aspecto moral e cultural, sobretudo porque a relevância de compreender a Família como célula da sociedade está em que toda reforma social efetiva deve ter início na Família.

A convivência familiar é um processo sociocultural no qual seus integrantes exercem atribuições e obrigações específicas, compartilham experiências e conhecimentos, pactuam regras de coabitação e disciplina. Orientando-se por modelos 
ou padrões de aprendizado, o ambiente familiar é autêntico espaço de experiência e ensino de valores, princípios e costumes. Nesse contexto, é certo ser a Família o primeiro agente de socialização da criança, o que o faz empregando os meios e conhecimentos existentes ao seu alcance para preparar o indivíduo à convivência em sociedade.

Esse raciocínio, de ser a Família agente de socialização da criança, encontra eco em Minguet (2013, p. 228), que afirma:

La familia es considerada como el espacio de intimidad donde se forman y reproducen los modelos de identidad personal y comunitaria; el lugar básico del aprendizaje de valores y recreación de comportamientos sociales; el espacio de reproducción de la cultura y en el que se forma el sentido de pertinencia, de tradición, de comunicación, en el que se aprenden las relaciones afectuosas y se desarrollan las competencias básicas; el núcleo social natural donde se moldea la conciencia individual, y el más importante y primer agente de socialización en una comunidad. (MINGUET, 2013, p. 228).

A literatura antropológica aponta a existência da Família praticamente em todas as sociedades humanas, da pré-história ao período contemporâneo, inclusive nas sociedades com hábitos sexuais e educativos diversos dos adotados por nossa sociedade ocidental. A educação familiar não está dissociada do contexto sociocultural, ao contrário, encontra-se unida ao modelo de vida experimentado pelo grupo de que faz parte. A cultura de um povo e os modelos socioeconômicos por ele adotados favorecem o direcionamento do aprendizado familiar para certos valores e hábitos, que podem ser benéficos ou prejudiciais à criança e ao adolescente. Nas sociedades patriarcais da Idade Média do ocidente era admissível e compartilhado o pensamento discriminatório de gênero, raça, cor e opção sexual, ponto de vista que era, inclusive, acolhido e aceito pela pessoa discriminada na maioria das vezes. Nesse sentir, a convivência familiar e a educação familiar podem ser apontadas 
como relação de pensamento e ação orientados em mesmos valores e objetivos, unidos de forma congruente.

Não obstante, o seio familiar, espaço de afeto e abrigo, crescimento e harmonia de seus integrantes, é também o ambiente no qual se podem expor crianças e jovens a episódios de vulnerabilidade e situação de risco, como o uso de substâncias entorpecentes lícitas ou ilícitas que causam dependência química, o envolvimento à prostituição, o convívio com práticas criminosas como a comercialização de drogas ilícitas, a violência doméstica e familiar ou ainda o crescimento em ambiente que não supra as necessidades mínimas da criança e do adolescente para o saudável desenvolvimento.

Como adverte Alonso-Geta (2003, p. 65-66), a influência desempenhada pelos genitores se sujeita a variáveis tais como o modo de interação e os modelos educativos exercidos pelos pais, a idade das pessoas envolvidas neste processo, o sexo dos pais, entre outros. Importante ainda é a compreensão e a interpretação que pais e filhos têm sobre o ambiente que os cerca e sobre a percepção que tem da realidade social. Para o autor é fundamental o estudo sobre os modelos educativos que na família se estabelecem a fim de explicar o processo de desenvolvimento dos filhos, ressaltando ser distintos os comportamentos e percepções desempenhados pelos envolvidos nos diferentes estágios de desenvolvimento. Isso porque na infância a criança não tem conhecimento e ciência acerca da determinação que sobre ela se exerce, ao passo que o adolescente é conhecedor e tem total consciência do contexto, crendo-se a si mesmo ator das circunstancias, o que introduz novas formas na interação familiar.

A educação familiar conta ainda, em seu processo de socialização dos membros do núcleo familiar, com certas variáveis. Elas referem-se à interação entre seus membros, a forma de emprego da autoridade, a expressão de sentimentos e emoções, o modo como seus integrantes resolvem os conflitos. Ainda, 
tem-se como importante para essas variáveis a transferência de valores e princípios, regras, porque estabelecem distintas formas de funcionamento familiar. Por tanto, com base nessas premissas, não é suficiente a ação, tampouco a mera influência sobre os filhos para que ocorra educação. O empreendimento educativo é uma ação propositada, dirigida a um fim específico, que é a evolução do ser humano e sua socialização para conviver entre o grupo social no qual faz parte. No entanto, o propósito geral dos pais e demais membros da família neste processo de aprendizado deve corresponder ao exercício de uma influência real sobre a criança e o adolescente, talhando suas condutas e hábitos, de acordo com certos valores.

\section{EDUCAÇÃO FAMILIAR - PROCESSO COGNITIVO CULTURAL E BIOLÓGICO DE PROCESSAMENTO DE INFORMAÇÕES PELO SER HUMANO}

No processo de educação familiar, tem fundamental relevância, o papel exercido pela cultura no ambiente de convivência da Família. A cultura propicia à criança e ao adolescente hábitos e modos de conduta por meio da herança genética, é um comportamento transmitido dos progenitores para os filhos a longo prazo. Conforme Alonso-Geta (2003, pp. 65-66), o comportamento assimilado pelos filhos é a parte mais significativa do comportamento total dos infantes, inclusive seus instintos ficam regidos em conformidade com os significados e as normas culturais introjetadas pelo entorno. A cultura atua como o maior modelador do sujeito, a partir de um sistema de transmissão-aquisição que se inicia no momento do nascimento da criança, e que o acompanha até seus últimos dias de existência. Cada pessoa tem um comportamento humano distinto, cujas particularidades têm origem na reprodução do comportamento dos genitores pelos filhos, que sintetizam seus costumes e modos de ser e pensar. 
Tal fato decorre da versatilidade existente no cérebro humano e do suporte potencialmente cultural e não genético dos comportamentos adaptativos (ALONSO-GETA, 2003, p. 65-66).

Minguet (2013, p. 232) compartilha com Alonso-Geta a noção de atuar o ambiente familiar como um autêntico contexto de aprendizado, para a autora:

La vida en familia representa ya en sí mesma una situación de experiencia privilegiada; el contexto familiar puede actuar como un auténtico contexto de aprendizaje de ciudadanía, proporcionando experiencias diferenciadas, comprensivas e integradoras, a través de las cuales los niños adquieren vivencias globalizadoras sobre la realidad social y una mayor preparación para una ciudadanía activa; [...] Teniendo en cuenta que los seres humanos obtienen información sobre la realidad que les rodea viendo, oyendo, tocando, sintiendo y probando, es fácilmente comprensible que los hijos, a través de todos los sentidos, capten, desde el nacimiento, gran cantidad de información desde la vida diaria en familia; de esta forma los hijos empiezan a construir la experiencia previa de ciudadanía desde la cual se van a enfrentar a los requerimientos sociales (MINGUET, 2013, p. 232).

Miguel (2003, p. 102) sustenta ser importante propiciar à criança toda espécie de experiências significativas na primeira infância, compreendendo como tais aquelas que proporcionam à estruturação de uma personalidade voltada por legítimos valores. Entretanto, deve-se ensinar por meio dos bons exemplos. É fundamental que pais tenham coerência em seus discursos e atos. Não devem adotar comportamentos que se afastem dos valores por eles ensinados aos filhos. Para o autor "[...] es sabido que las experiencias más fuertes las vive el ser humano durante los primeros años de vida y en el seno de la familia. Los niños no descubren los valores en lo que les decimos, sino en lo que nos ven que hacemos." (MIGUEL, 2003, p. 102).

A criança em idade tenra está munida de um leque amplo de oportunidades, que aciona ao entrar em contato com 
as distintas formas de intervenção sociocultural as que se vê submetida. Nesse sentido, em ambientes familiares em que se fomenta a amizade e a cooperação do grupo, os comportamentos hostis e violentos são refutados, se encontram sobretudo controlados, como é o caso dos Tasaday de Mindanao, o Ifaluks do Pacífico ou os Pigmeus do Bosque Ituri. É um comportamento tão raro que, quando se apresenta, considera-se como um sinal de anormalidade e por tal é prontamente reprimido. Nesses grupos, as potencialidades genéticas não receberam os estímulos suficientes para a propagação do comportamento agressivo. (ALONSO-GETA, 2003, p. 67).

De outro norte, o desenvolvimento de um comportamento agressivo e hostil é favorecido em grupos de pessoas no qual se fomenta a violência em suas distintas formas (física, psíquica, moral, sexual). Há pesquisas transculturais conclusivas no sentido de que o rol de emoções precípuas, como felicidade, tristeza, dor, surpresa, exteriorizadas pelas crianças manifestam-se em todas as culturas. Em síntese, o ser humano já nasce com potencial para executar as expressões faciais correspondentes a emoções básicas, todavia os contextos que as instigam diferem de acordo com dado espaço sociocultural.

O indivíduo é dotado de qualidades biológicas, as quais, com estimulação adicional e apropriada dos pais, em seu ambiente familiar e cultural, se manifestam. Nosso aparato biológico nos propiciaria conhecer, sentir e vivenciar distintos modelos de cultura existentes, seus costumes e comportamentos. Porém, nosso desenvolvimento ocorre, em regra, em apenas um modelo sociocultural: o ambiente familiar em que fomos criados.

Este processo de modelação do comportamento humano, no qual o sistema biológico é plasmado pelos aspectos culturais de determinado povo, tem início no grupo familiar e se propaga por meio de estímulos educativos à criança e ao adolescente. Seguindo este raciocínio, certo é afirmar que o com- 
portamento de cada pessoa é formado pelos fatores genéticos e socioculturais de dado espaço e tempo.

$\mathrm{Na}$ acepção mais clássica da pedagogia, a Família constitui o primeiro conjunto de estímulos educativos para o desenvolvimento intelectual, moral e social da criança. Para López (2004, p. 09), a educação familiar possibilita diferenciar características pessoais, materiais e formais, atuando fundamentalmente sobre circunstâncias qualificativas da própria vida e educação. Essas circunstâncias configuram as áreas específicas da educação familiar, como a formação da personalidade e dos juízos de valor, segundo os quais "la familia es la paidocenosis fundamental. Las paidocenosis son conjuntos de estímulos vinculados, tan estrechamente, que llegan a formar un todo determinante de un particular tipo de educación." (LÓPEZ, 2004, p. 09).

Como assinalamos, os modelos educativos intervém significativamente na formatação da personalidade dos filhos, transmitindo preceitos e lições que influenciam a autoestima, as habilidades emocionais, as habilidades cognitivas, etc. De todo modo, o conteúdo disseminado aos filhos resulta dos valores e princípios aceitos pelos pais e dos valores predominantes no contexto sociocultural em que cada família esteja inserta. Os valores e os princípios têm singular relevância no processo de socialização da criança e do adolescente, pois configuram preceitos dirigentes do sistema de juízos e de comportamento do indivíduo perante a sociedade. A conduta do ser humano é pautada pelos valores transmitidos pelos pais e pela escola. (ALONSO-GETA, 2003, p. 75).

Corroborando nesse sentido, Miguel (2003, p. 102) adverte ser preciso conhecer quais valores se encontram na base de um sistema educativo, já que eles vincularão o perfil de ser humano e, por consequência, de sociedade que estaremos edificando. Família, escola e sociedade não educam sem valores. O comportamento adotado pelo ser humano depende dos valores que 
tenham sido por ele interiorizados, a partir de propostas à sua experiência de vida. "Los valores son una propuesta de vida que solo se percibe cuando se encarnan en la realidad. Los valores no se demuestran, se muestran encarnados en las personas que sirven de modelo al educando." (MIGUEL, 2003, p. 102).

Os filhos são instruídos historicamente nas habilidades, nos valores e conhecimentos básicos repassados pelas gerações anteriores, mediante um processo regular, cujo entorno familiar tem papel fundamental. Todavia, nos últimos tempos, a família tem vivenciado expressivas modificações em seu modo de relacionar-se e de convivência. Trata-se de uma transformação sociocultural que tem como origem vários fatores, tais como a globalização, o sistema de produção capitalista, as novas tecnologias da comunicação, como WhatsApp, Facebook, Skype, etc.

Realçando o processo de transformação que a Família vem participando nas últimas décadas, Anthony Giddens (2007, p. 22-23) defende ter a globalização contribuído para este fenômeno. Para o autor, é equivocado acreditar que a globalização incida apenas nos grandes sistemas, como a ordem financeira mundial, já que a globalização afeta pontos íntimos e pessoais de nossas vidas, como as relações familiares e seus valores. Logo, a globalização não se trata de um processo singular, que afeta a economia externa, mas um conjunto complexo de processos, que repercutem no comportamento, interesses e modo de pensar da sociedade civil. Conforme o autor:

[...] o debate sobre valores familiares que está se desenvolvendo em vários países, por exemplo, poderia parecer muito distanciado de influências globalizantes. Mas não é. Sistemas tradicionais de família estão começando a ser transformados, ou estão sob tensão, especialmente à medida que as mulheres reivindicam maior igualdade. Até onde sabemos pelo registro histórico, jamais houve antes uma sociedade em que as mulheres fossem sequer aproximadamente iguais aos homens. Esta é uma revolução verda- 
deiramente global da vida cotidiana, cujas consequências estão sendo sentidas no mundo todo, em esferas que vão do trabalho à política. (GIDDENS, 2007, p. 22-23).

Corroborando sobre o poder que exerce a educação familiar sobre o comportamento dos filhos, Estébanez (2003, p. 31) ressalta serem notórias as implicações do meio familiar sobre os mecanismos de personalização, socialização e moralização de crianças e adolescentes. A formação de elementos constitutivos da personalidade como o autoconceito, a autoestima, o sentimento de identidade, o estilo de resposta à estimulação e a organização perceptiva do mundo das crianças, são condicionados pelo ambiente familiar, que fornece segurança e proteção aos infantes como ser em processo de desenvolvimento. Em tal medida, os filhos absorvem as noções éticas, morais e de justiça transmitidas pelos pais. Inicia-se por ser heterônomo, pois o principal parâmetro que a criança dispõe ao seu alcance para julgar a bondade de ações humanas é aquele assimilado dos pais e dos membros da família.

Embora na juventude este parâmetro possa ser remodelado, por introjetar, no indivíduo, valores adquiridos nas demais relações sociais (amigos e instituições), em regra, perdurará o conteúdo básico absorvido na primeira infância. Em virtude de se apresentar por primeira vez na vida da criança, a interação familiar tem azo na socialização primária, a partir da comunicação entre mãe-filho. Defendem especialistas ser tamanha a relevância dessa interação diádica que, apresentando-se ausente ou interrompida, pode levar a sérios transtornos de personalidade, entre os quais se aponta o autismo. (ESTÉBANEZ, 2003, p. 31-32).

Por sua vez, as "instâncias paternas", denominação psicanalítica que representa a função dos progenitores ou de quem os substitui - cuidadores, tutores, pais adotivos, pais socioafetivos, etc. -, é objeto de estudo das pedagogias influenciadas por alguma das muitas psicologias profundas ou psicanalíticas. Referidas disciplinas têm reservado especial atenção para in- 
vestigar a contribuição dos genitores, porque determinantes de reações inconscientes dos filhos. Nesse sentido, como sustenta Estébanez (2003, p. 42), as instâncias paternas interagem com a criança e o adolescente plasmando a personalidade, a socialização, a moralização e, acrescentamos, os juízos de valores. A confluência das instâncias maternas e paternas, com os atributos outorgados pela psicanálise a cada uma dessas instâncias, possui determinante contribuição na saúde mental dos filhos, bem como para o progresso da personalidade. A personalidade, a partir dos elementos apresentados, é resultado do código genético e da intercomunicação efetivada no seio da relação familiar, na qual cada interlocutor tem função especial.

La relación afectiva de los padres, de los hermanos y de los otros posibles familiares convivientes bajo el mismo techo es definitiva en el desarrollo de la personalidad de los hijos, tal y como han demostrado las investigaciones sobre la impronta o troquelado, el "apego", la relación diádica, las carencias y el aprendizaje de patrones de conducta. El padre y la madre intervienen, por el mero hecho de representar la masculinidad y la femineidad, en la tipificación sexual y en todos los demás procesos de identificación. (ESTÉBANEZ, 2003, p. 42).

Esta relação de interação familiar entre pais e filhos determina também a socialização do indivíduo, de modo embrionário, justamente por iniciar o desenvolvimento das habilidades sociais. Estas habilidades qualificam os filhos a estabelecer relação de empatia com os demais integrantes de seu meio social. Correlata à evolução social está o desenvolvimento ético.

\section{A EDUCAÇÃO PARA A SUSTENTABILIDADE COMO PROPÓSITO DA FUNÇÃO SOCIAL DA FAMÍLIA}

Antes de iniciarmos a tratativa sobre o tema proposto, para excluir eventuais interpretações divergentes sobre categorias importantes expostas no texto, evitando o uso do senso co- 
mum, que, para uma adequada pesquisa científica não é recomendado, apresentaremos o conceito operacional da expressão função social da Família. Essa tarefa é aconselhável para facilitar a compreensão do leitor acerca dos argumentos que se pretende justificar na redação do trabalho, dinamizando as reflexões e discussões surgidas no decorrer da leitura ${ }^{3}$.

Nesse sentido, compreende-se por função social da família o conjunto de incumbências atribuídas à Família, consistentes em práticas positivas de convivência familiar sustentável que propiciem a valorização do ser, pelos laços de afeto e carinho; da dignidade da pessoa humana e da fraternidade, para construção de uma sociedade livre, justa e solidária; e com fundamento na sustentabilidade e na boa-fé. Esta função social da família tem por objetivo contribuir no desenvolvimento de seus membros, apoiados em valores constitucionais, promovendo a justiça social e colaborando para a promoção da cidadania em benefício de uma Sociedade livre de desigualdades sociais ${ }^{4}$.

A Família, por ser classificada como núcleo fundamental da sociedade e por receber especial atenção do Estado, prevista, em regra, nas constituições de cada Estado soberano, tem seus direitos e obrigações disciplinados por legislação. Seguindo esta lógica o art. 39 da Constituição Espanhola dispõe que "Los poderes públicos aseguran la protección social, económica y jurídica de la família", (ESPANHA, 1978) e o art. 226 da Constituição da República Federativa Brasileiraressalta ser a família "base da sociedade” e ter “especial atenção do Estado.” (BRASIL, 1988).

Conforme Neira (2003, p. 14) o objetivo é disciplinar as relações familiares e proteger a família, na medida em que ela

3 Conforme bem justifica Pasold (2015, p. 52), o senso comum muitas vezes não é o que o bom senso recomenda para uma dada situação científica, até porque, em Ciência, o óbvio deve ser desconsiderado para uma adequada pesquisa científica.

4 Este é o conceito operacional proposto pelo autor, que, embora sucinto diante da abrangência do tema, decorre do levantamento bibliográfico realizado no decorrer do curso de Doutorado em Direito pela UNIVALI. 
representa processo de evolução da vida humana. "Todas las Constituciones de los países civilizados, incluso las de los del Este europeo y asiáticos, se preocupan y regulan la institución de la familia, estableciendo unos principios básicos para su protección.”(CACHARRÓN, 1988, p. 186).

Corroborando a assertiva de ser a família essencial para a sociedade, o art. 16, 3, da Declaração Universal dos Direitos Humanos, destaca que "A família é o elemento natural e fundamental da sociedade e tem direito à proteção da sociedade e do Estado." (ONU, 1948).

A fim de garantir condições favoráveis para o desenvolvimento da família e seus membros, a Declaração Universal de Direitos Humanos enumera um rol de direitos sociais a todo ser humano a fim de garantir uma qualidade de vida digna, suficiente para propiciar a si e a sua família saúde, bem-estar, inclusive alimentação, vestuário, habitação, cuidados médicos e os serviços sociais indispensáveis e direito à segurança em caso de desemprego, doença invalidez, viuvez, velhice, etc.

No plano nacional, a função social da família encontra apoio no art. 226 da CRFB. (BRASIL, 1988). Este preceito assinala ser a Família, a base da sociedade e por tal merece especial proteção do Estado. Embora seja norma impositiva, não se aplica em sua integralidade, pois em diversos casos o Estado e a Sociedade não asseguram a assistência à Família.

De outro viés, no plano internacional, resoluções apontam sobre a necessidade e consequente importância de introjetar a educação para a sustentabilidade em todos as etapas do processo educativo. Comprova essa afirmação, a função concedida à educação na edificação de um futuro sustentável, tanto pela UNESCO como pela Organização das Nações Unidas, a partir do Decênio da Educação para o Desenvolvimento Sustentável (DEDS) 2005-2014, que suscitou, em 2015, ao Programa de Ação Global de Educação 
para o Desenvolvimento Sustentável. (UNESCO, 2014).

O Programa de Ação Global de Educação para o Desenvolvimento Sustentável foi aprovado pela Conferência Geral da UNESCO com duas grandes intenções (UNESCO, 2014a): 1reorientar a educação e o aprendizado - concebidos como um processo permanente, que deve chegar a todas pessoas - de forma que se favoreça a obtenção de conhecimento, valores, atribuições, a das atitudes que são necessárias para construção de uma Sociedade sustentável e pacífica, respeitosa com a diversidade cultural e o meio ambiente; 2 - reforçar o papel da educação em todos os planos de ação, programas e atividades orientadas a este modelo de desenvolvimento, atuando a favor da integridade do meio ambiente e da viabilidade da economia em um mundo mais justo, tolerante, inclusivo e seguro. (CARIDE GÓMEZ, 2017, p. 249).

Não obstante, conforme advertem Gil Pérez e Vilches (2017, p. 79), em que pese este reconhecimento internacional da educação como veículo de transição à sustentabilidade, os progressos obtidos em sua inclusão no modelo educativo são insuficientes, como apontam diversos estudos sobre este tema.

Nesse diapasão, como já exposto anteriormente, o processo de aprendizado e de educação de crianças encontra aporte inicial na Família, como unidade primária de aprendizado. Pais, irmãos e demais integrantes da mesma família colaboram no desenvolvimento da personalidade e crescimento cognitivo da criança, por meio de um processo diuturno, continuado e muitas vezes imperceptível. A Família repassa valores, costumes, hábitos, conhecimentos, que podem ser positivos ou negativos à formação da criança e do adolescente.

A educação familiar é provida em conformidade com os aspectos socioculturais de cada espaço territorial e dado momento histórico. O desfecho desta educação decorre ainda de certas variáveis como idade dos pais, gênero dos genitores, 
situação econômica da Família, grau de escolaridade dos pais, comprometimento dos genitores com a educação dos filhos. De outro vértice, é fundamental o suporte do Estado e da Sociedade para implementação de instrumentos que facilitem essa tarefa educativa no ambiente familiar ${ }^{5}$.

De fato, Estado e Sociedade devem fornecer à função social da família, elementos suficientes para propiciar a educação para a sustentabilidade ambiental, econômica e social. Esta educação dede ser orientada à valorização do ser, pelos laços de afeto e carinho, da dignidade da pessoa humana e da fraternidade, para construção de uma Sociedade livre, justa e solidária.

Ao encontro do tema, Caride Gómez (2017, p. 245) refere que a participação direta da Sociedade na solução dos problemas ambientais e na construção da sustentabilidade, com uma visão crítica e prospectiva que propicie uma transformação abrupta nas práticas da atual forma de desenvolvimento, não se poderá fazer sem uma educação ambiental e social, que se implante na vida cotidiana da população.

\section{CONCLUSÃO}

Conforme proposto inicialmente, o objetivo deste artigo científico foi discorrer sobre a educação familiar como processo de aprendizado primário do ser humano, justificando sua importância para o desenvolvimento da personalidade e crescimento cognitivo da criança e do adolescente, em especial, como instrumento de educação para a sustentabilidade.

E nesse sentido, compreendemos que a exposição, embora de modo singelo, apresentou os principais aspectos da Educação Familiar e seu mérito como recurso viável para a disseminação da

5 Neste trabalho, adotando o mesmo raciocínio de Pasold, (2013, p.10) a categoria Sociedade é empregada com a inicial maiúscula por ser a criadora e mantenedora da categoria o Estado, que, grafada com a inicial maiúscula, deve estar comprometida e atender os fins sociais desejados pela Sociedade. 
educação para a sustentabilidade entre crianças e adolescentes. A implantação da cultura de sustentabilidade global e preservação do meio ambiente requer a aplicação de políticas públicas que favoreçam o aprendizado desses temas no ambiente familiar.

Por esse motivo, o Programa de Ação Global de Educação para o Desenvolvimento Sustentável da UNESCO manifesta entre seus objetivos: 1 - reorientar a educação e o aprendizado para construção de uma Sociedade sustentável; e, 2 - reforçar o papel da educação em todos os planos de ação, programas e atividades orientadas ao modelo de desenvolvimento sustentável.

É imprescindível a mudança de consciência dos habitantes do planeta, que somente será possível a partir da adoção de incentivos e projetos do poder público e da Sociedade para fortalecimento da Família e de sua função como protagonista da Educação Familiar.

Seguindo esse raciocínio, Minguet e Solís (2013, p. 12) alertam para a necessidade da mudança de consciência, esclarecendo que

La consecución de un desarrollo humano inclusivo, ambiental y socialmente sostenible presupone cambiar de forma significativa las pautas actuales de desarrollo, producción, consumo y comportamiento. Y estos cambios implican compartir la responsabilidad a escala mundial, comunitaria, regional, local y también personal.

Estado e Sociedade civil devem compreender que a educação familiar, como primeiro agente de socialização do ser, merece adequada atenção pelas políticas públicas, ações e medidas direcionadas a implementação de instrumentos que facilitem essa tarefa educativa no ambiente familiar.

Como defende Miguel (2003, p. 102), é necessário conhecer e refletir quais valores estão na base de um sistema educativo, já que eles vincularão o perfil de ser humano e, por consequência, de Sociedade que estaremos edificando. O comportamento ado- 
tado pelo ser humano depende dos valores que tenham sido por ele interiorizados, a partir de propostas à sua experiência de vida.

\section{REFERÊNCIAS}

ALONSO-GETA, Petra Maria Perez. Crianza y estilos familiares de educación. 2003.

CACHARRÓN, Jesús Seoane. Educación familiar y delincuencia juvenil. In: Familia y Educación. GONZÁLES, Eusebio. (Coord). Madrid: Ediciones Rialp, S.A, 1988.

CARIDE GÓMEZ, José Antonio. Educación social, derechos humanos y sostenibilidad en el desarrollo comunitario. Teoría de la educación. Revista Interuniversitaria, Salamanca, v. 29, n. 1, p. 245-272, jun. 2017. Disponible en: <http://revistas.usal.es/ index.php/1130-3743/article/view/teoredu291245272>. Acesso em: 14 set. 2017.

ESPAÑA. Constituição Española de 1978. Congreso de los diputados. Madrid, Es. Disponível em: <http://www.congreso.es>. Acesso em: 7 out. 2017.

ESTÉBANEZ, Paciano Fermoso. Relaciones familiares: pareja, paternidad y fratría. 2003.

GIDDENS, Anthony. Mundo em descontrole. O que a globalização está fazendo de nós. Tradução Maria Luiza X. de A. Borges. 7. ed. Rio de Janeiro: Editora Record, 2007.

GIL PÉREZ, Daniel; VILCHES, Amparo. Educación para la sostenibilidad y educación en derechos humanos: dos campos que deben vincularse. Teoría de la educación. Revista Interuniversitaria, Salamanca, v. 29, n. 1, p. 79-100, jun. 2017. Disponible en: $<$ http://revistas.usal.es/index.php/1130-3743/article/view/teoredu29179100>. Acesso em: 14 set. 2017.

LÓPEZ, José Manuel Touriñán. Familia, educación y sociedad civil. In: Familia, educación y sociedad civil. Servicio de publicación e intercambio científico campus universitario sur: Santiago de Compostela, 2004.

MIGUEL, Antonio Escaja. Educar en família: propuestas para una educación preventiva. Editorial CCS: Madrid, 2003.

MINGUET, Pilar Aznar (Coord.); SOLÍS, Maria Ángeles Ull. La responsabilidad por un mundo sostenible: propuestas educativas a padres y profesores. Bilbao: Editorial Desclée de Brouwer S.A, 2013.

NEIRA, Teófilo. Pedagogía y educación familiar. In: Educación familiar: Nuevas relaciones humanas y humanizadoras. R. GERVILLA, Enrique. (Coord). Madrid: Narcea, S.A. de Ediciones, 2003.

ORGANIZAÇÃO DAS NAÇOES UNIDAS. Declaração universal dos direitos humanos 1948. Disponível em: <http://www.unicef.org>. Acesso em: 7 out. 2017.

PASOLD, Cesar Luiz. Função social do estado contemporâneo. 4. ed. rev. amp. Itajaí, SC: Univali, 2013. Disponível em: [e-book] <http://siaiapp28.univali.br/LstFree.aspx>.

. Metodologia da pesquisa jurídica: teoria e prática. 13. ed. rev. atual. amp. Florianópolis: Conceito Editorial, 2015. 